\title{
Combined segregation and linkage analysis of inflammatory bowel disease in the IBD1 region using severity to characterise Crohn's disease and ulcerative colitis
}

\author{
Paola Forabosco ${ }^{1}$, Andrew Collins ${ }^{2}$, Anna Latiano ${ }^{3}$, Vito Annese ${ }^{3}$, Maurizio Clementi ${ }^{4}$, \\ Angelo Andriulli ${ }^{3}$, Paolo Fortina ${ }^{5}$, Marcella Devoto $^{6}$ and Newton E Morton ${ }^{2}$, on behalf of \\ the GISC

\begin{abstract}
${ }^{1}$ Istituto di Genetica Molecolare CNR, Alghero, Italy; ${ }^{2}$ Department of Human Genetics, Genetic Epidemiology, Southampton General Hospital, Southampton, UK; ${ }^{3}$ Divisione di Gastroenterologia, Ospedale CSS-IRCCS, San Giovanni Rotondo, Foggia, Italy; ${ }^{4}$ Dipartimento di Pediatria, Università di Padova, Italy; ${ }^{5}$ Department of Pediatrics, University of Pennsylvania School of Medicine and The Children's Hospital of Philadel phia, USA; ${ }^{6}$ Dipartimento di Oncologia Clinica e Sperimentale, Università di Genova, Italy and AI duPont Hospital for Children, Wilmington, USA
\end{abstract}

Inflammatory bowel disease (IBD) is a chronic relapsing disorder affecting the gastro-intestinal tract and is subdivided into two main subtypes: Crohn's disease (CD) and ulcerative colitis (UC). Although the aetiology of IBD is unknown, a strong genetic susceptibility is suggested and different candidate regions have been identified for both CD and UC. The IBD1 region on chromosome 16 has been confirmed to be important for susceptibility to $C D$, whereas conflicting evidence has been obtained for UC. We performed a combined linkage and segregation analysis in the identified IBD1 region on a sample of 82 extended families with IBD using a parametric method implemented in the computer program COMDS. This approach allows simultaneous evaluation of linkage while estimating the mode of inheritance and to include severity of the trait to characterise the CD and UC phenotypes. Our results are consistent with the presence of a major gene in the IBD1 region close to D16S408 involved in both UC and CD. Furthermore, our data support evidence that a single mutation in the gene leads more frequently to UC, whereas inheritance of two mutant alleles results in the more severe CD. In our study the IBDI locus was found to have a major role in IBD predisposition in the Italian population. European Journal of Human Genetics (2000) 8, 846-852.

Keywords: Inflammatory bowel disease; segregation analysis; linkage; IBD1

\section{Introduction}

Inflammatory bowel disease (IBD) is a chronic relapsing disorder affecting the gastro-intestinal tract with a population prevalence in Western societies of $1: 1000 .^{1}$ IBD is subdivided on the basis of clinical and histologic features

Correspondence: Dr Paola Forabosco, Istituto di Genetica Molecolare-CNR, Località Tramariglio, 07041 Alghero (SS), Italy. Tel: +39079946713; Fax: +39079946714;

E-mail: paola@genet3.unimo.it

Received 25 February 2000; revised 28 June 2000; accepted 30 June 2000 into two subtypes: Crohn's disease (CD) and ulcerative colitis (UC). ${ }^{2}$

Although the aetiology of IBD is unknown, a strong genetic susceptibility is shown by epidemiological data. ${ }^{3-6}$ Both forms of IBD can co-exist in single families, and the associated risk of developing the other form of the disease is also increased in relatives of affected subjects, suggesting the presence of shared susceptibility genes between the two diseases. $^{7}$

Previous segregation analysis studies performed on CD and UC families separately have indicated the presence of a major 
gene leading to recessive inheritance for $C D$ as well as one resulting in dominant and additive inheritance for $\mathrm{UC}^{8-10}$ although the identified major genes were estimated to account only for a small proportion of cases.

Several susceptibility loci contributing to the genetic risk for IBD have been identified in different chromosomal regions through genome-wide searches. ${ }^{11-16}$ The importance of the candidate loci on chromosome16 (IBD1, MIM 266600), chromosome12 (IBD2, MIM 601458) and chromosome6 (IBD3, MIM 604519) has been demonstrated in subsequent studies, ${ }^{17-26}$ whereas the additional IBD loci need to be confirmed by further independent analyses.

Recently we have confirmed through a non-parametric approach the involvement of the IBD1 locus in an independent sample of Italian IBD families. ${ }^{26}$ We now present a parametric analysis performed on an extended sample employing combined segregation and linkage analysis in the identified IBDI region. Using this approach it is possible to test linkage and to refine the mode of disease inheritance using the information provided by the linked marker, thus allowing more accurate estimates of the genetic parameters, such as gene frequency and pen etrance and, consequently, a more powerful test for linkage. Furthermore, the role of the IBDI locus in CD and UC aetiology is investigated.

\section{Subject and methods Family data}

Combined segregation and linkage analysis was performed on a sample of 82 extended families with IBD, ascertained through 34CD-affected probands and 48UC-affected probands in the multicentre programme of the GISC (Italian Group for the Study of the Colon and the Rectum). Description of families, selection scheme and total number of affected and unaffected individuals subjected to analysis are shown in Table1. Extended pedigrees were decomposed before the analysis into nuclear families with the inclusion of pointers, who are affected relatives through whom the nuclear family was ascertained. ${ }^{27}$ Pointers were coded as defined in Morton et al. ${ }^{28}$ The different combinations of parental phenotypes and selection criteria of the resulting nuclear families are shown in Table2.

Liability classes were specified prior to the analysis to correct for covariates with affection, as in the usual formulation of the liability model. ${ }^{29}$ Age of observation was available only for 19 of the 82 families; therefore, when age was not specified, three age classes were formed corresponding to the generation of the pedigree member (Table 3). Population risks for each liability class were derived from Orholm et al, ${ }^{10}$ since age-specific risk estimates based on a large population survey are not available for the Italian population. Although sporadic reports have suggested a lower incidence rate for IBD in Italy, an increasing trend has also been reported. ${ }^{30}$

In order to investigate the mode of inheritance of the IBD trait, the whole sample of 82 families was studied, defining affecteds as those with either CD or UC. Information on severity (see Statistical analysis) was included in the analysis of the IBD sample by forming two severity classes among affected subjects: UC-affected patients were assigned to the less severe class and CD-affected patients to the more severe class. This classification reflects the clinical features of the disease: UC is largely a mucosal disease restricted to the large intestine, whilst in CD the entire thickness of the bowel is affected and it may involve any part of the gastrointestinal tract. The relative proportions among affected individuals estimated from our sample for UC and CD were 0.618 and 0.382 , respectively.

Combined segregation and linkage analysis was also performed separately for each sub-group of the whole IBD family sample (CD only, UC only, and CD/UC families) and tests of heterogeneity were carried out.

Eight markers spanning approximately $30 \mathrm{cM}$ of the IBD1 region (D16S517, D16S409, D16S411, D16S419, D16S408,

Table 1 Description of families, selection scheme* and total number of affected and unaffected individuals included in the analysis

\begin{tabular}{|c|c|c|c|c|c|c|}
\hline Affected relatives & $C D$ & $\begin{array}{l}\text { No. of families } \\
\text { UC }\end{array}$ & $C D / U C$ & $\begin{array}{l}\text { Total no. } \\
\text { affected }\end{array}$ & $\begin{array}{l}\text { Total no. } \\
\text { unaffected }\end{array}$ & $\begin{array}{l}\text { Secondary } \\
\text { proband }\end{array}$ \\
\hline 2 sibs & 8 & 13 & 9 & 60 & 89 & \\
\hline 2 sibs + 1 first cousin & 1 & - & - & 3 & 1 & 1 \\
\hline 2 sibs + 1 niece/nephew & - & 1 & - & 3 & 6 & \\
\hline 2 sibs +1 parent & - & 3 & 1 & 12 & 6 & \\
\hline 3 sibs & 1 & - & 1 & 6 & 2 & \\
\hline 4 sibs & 1 & - & - & 4 & 10 & \\
\hline 1 aunt/uncle; 1 niece/nephew & 2 & 1 & 4 & 14 & 31 & \\
\hline 2 first cousins & - & 1 & 1 & 4 & 11 & 2 \\
\hline 2 first cousins +1 parent & - & 1 & - & 3 & 5 & 1 \\
\hline 1 grandparent; 1 grandchild & 1 & 1 & 1 & 6 & 9 & \\
\hline 1 parent; 1 child & 3 & 13 & 6 & 44 & 52 & \\
\hline Singleton & 4 & 4 & - & 8 & 26 & \\
\hline Total & 21 & 38 & 23 & 167 & 248 & 4 \\
\hline
\end{tabular}

*Pedigree information on first and second degree relatives of affected probands was obtained when possible (single selection of pedigrees), whereas more distant branches of pedigrees were sampled only when they included an affected relative (secondary proband). 
Table 2 Distribution by ascertainment and mating type of the nuclear families subjected to the analysis

\begin{tabular}{|c|c|c|c|}
\hline Ascertainment selection & $\mathrm{N} \times \mathrm{N}$ & $\begin{array}{l}\text { Mating type }^{a} \\
N \times A\end{array}$ & $\mathrm{~N} \times \mathrm{U}$ \\
\hline $\begin{array}{l}\text { IBD nuclear families } \\
\text { complete selection (proband as a parent) } \\
\text { complete selection (selection through a pointer }{ }^{\mathrm{b}} \text { ) } \\
\text { incomplete selection (proband as a child) } \\
\text { truncate selection (secondary proband) }\end{array}$ & $\begin{array}{l}0 \\
19 \\
57 \\
4\end{array}$ & $\begin{array}{l}22 \\
4 \\
14 \\
0\end{array}$ & $\begin{array}{l}0 \\
1 \\
1 \\
0\end{array}$ \\
\hline $\begin{array}{l}\text { CD-only nuclear families } \\
\text { complete selection (proband as a parent) } \\
\text { complete selection (selection through a pointer }{ }^{\mathrm{b}} \text { ) } \\
\text { incomplete selection (proband as a child) } \\
\text { truncate selection (secondary proband) }\end{array}$ & $\begin{array}{l}0 \\
6 \\
17 \\
1\end{array}$ & $\begin{array}{l}5 \\
1 \\
1 \\
0\end{array}$ & $\begin{array}{l}0 \\
0 \\
1 \\
0\end{array}$ \\
\hline $\begin{array}{l}\text { UC-only nuclear families } \\
\text { complete selection (proband as a parent) } \\
\text { complete selection (selection through a pointer }{ }^{b} \text { ) } \\
\text { incomplete selection (proband as a child) } \\
\text { truncate selection (secondary proband) }\end{array}$ & $\begin{array}{l}0 \\
5 \\
23 \\
2\end{array}$ & $\begin{array}{l}11 \\
2 \\
9 \\
0\end{array}$ & $\begin{array}{l}0 \\
1 \\
0 \\
0\end{array}$ \\
\hline $\begin{array}{l}\text { CD/UC nuclear families } \\
\text { complete selection (proband as a parent) } \\
\text { complete selection (selection through a pointerb) } \\
\text { incomplete selection (proband as a child) } \\
\text { truncate selection (secondary proband) }\end{array}$ & $\begin{array}{l}0 \\
8 \\
17 \\
1\end{array}$ & $\begin{array}{l}6 \\
1 \\
4 \\
0\end{array}$ & $\begin{array}{l}0 \\
0 \\
0 \\
0\end{array}$ \\
\hline
\end{tabular}

${ }^{a} \mathrm{~N}=$ normal, $\mathrm{A}=$ affected, $\mathrm{U}=$ unknown status; ${ }^{\mathrm{b}}$ nuclear families with the parent of the proband as a child.

Ascertainment probability was set to 0.001 for incomplete selection and to 1.0 for truncate selection.

Table 3 Liability classes $^{\mathrm{a}}$ for IBD, CD, and UC specified in the analysis

\begin{tabular}{lllll}
\hline Liability class & Age class or generation & CD & UC & IBD \\
\hline 1 & $<30$ years or 3rd generation & 0.000810 & 0.001473 & 0.002283 \\
2 & $\geq 30$ and $<50$ years or 2nd generation & 0.001575 & 0.004742 & 0.006317 \\
3 & $\geq 50$ years or 1st generation & 0.001203 & 0.004409 & 0.005612 \\
\hline
\end{tabular}

aerived from Orholm et al. ${ }^{10}$

D16S514, D16S503, and D16S421) were tested for linkage using a two-point approach and simultaneously estimating the parameters of the genetic model. When linkage to a marker was observed, further tests allowing more general genetic models were done.

\section{Statistical analysis}

Statistical analysis was done using COMDS, a computer program for COMbined segregation and linkage analysis with Diathesis and Severity. Full documentation about the model can be found in Morton et al. ${ }^{31}$

In the COMDS program two autosomal disease loci can be considered: a major disease locus, linked to a marker locus, and a modifier locus, although the modifier locus does not necessary have the smaller effect. The two loci are biallelic with a high and a low risk al lele, and their effects are assumed to be additive on the liability scale. Parameters of the genetic model are: frequency of the alleles favouring high liability ( $q$, $\left.q_{m}\right)$, degree of dominance $\left(d, d_{m}\right)$, ranging from 0 for $a$ recessive trait to 1 for a dominant one, displacement between homozygotes $\left(t, t_{m}\right)$, and the recombination fraction, $\theta$, between the major gene and the marker locus.
Complex phenotypes are included in COMDS by forming severity classes among affected subjects through a subclassification ordered by increasing severity. A severity scale is assumed for affected individuals: on this scale the effect of each locus is modelled by a scaling parameter, S for the major and $S_{m}$ for the modifier locus, so that $S t$ and $S_{m} t_{m}$ represent the distance between homozygotes. Therefore, when $\mathrm{S}=0$ there is no genotypic difference between individuals of different severity classes and the major locus has no effect on severity of disease; when $\mathrm{S}>0$ the genotypic difference between individuals of two adjacent severity classes can be less $(S<1$ ) or more (when $S>1$ ) than the difference between affected and normal individuals. When $S>1$, the effect of the major locus on severity is therefore greater than its effect on affection.

Parameter estimates of the genetic model are obtained by maximising the likelihood function of the observed phenotypes in families using joint likelihood. Support for a particular hypothesis is obtained by maximum likelihood ratio test (LRT): the test statistic $2\left(\mathrm{InL}_{\text {general model }}{ }^{-}\right.$ $\left(n L_{\text {restricted model }}\right)$ is distributed in large samples as $\chi^{2}$ with degrees of freedom equal to the difference of the number of parameters estimated in the two models. LRT is based on 
comparison of hierarchical models (the restricted model must be a subset of the general one). For non-hierarchical models. Akaike's information criterion ${ }^{32}$ can be used to identify the most parsimonious model.

When testing for linkage to a marker locus, lod scores are calculated as the $\log _{10}$ of the ratio between the likelihood obtained with $\theta$ estimated and the likelihood with $\theta$ constrained to 0.5 , under a specific genetic model.

\section{Results}

Results of the COMDS analysis for the whole IBD sample are reported in Table4. In this analysis affected individuals were defined as having IBD, thus including those with either CD or UC.

When linkage and severity were not considered the major dominant and recessive modifier model provided the best fit (model 5). This two-loci model was significantly better than the single major locus (model 4 vs model 5: $\chi^{2}=9.9,3 \mathrm{df}$, $P=0.0194)$. Taking severity of the disease into account, a significant improvement of the likelihood was observed for the two-loci model with an estimated severity parameter $>0$ for the recessive modifier locus (model 5 vs model 6 : $\chi^{2}=12.87,1 \mathrm{df}, \mathrm{P}=0.0002$ ), whereas the likelihood was not improved when estimating $\mathrm{S}$ for the dominant major locus (data not shown), indicating a main effect of the recessive modifier gene on severity of the disease.

When linkage was tested for the eight markers spanning the IBD1 region, the best evidence of linkage was obtained at marker D16S408, where a lod score of 2.93 at a recombination fraction of 0.0 was observed for the two-loci model (model 8) and a lod score of 4.14 (for $\theta=0.0$ ) was obtained for the single-locus dominant model (model 7). The two-loci model did not provide a significant better fit than the singlelocus dominant model (model 7 vs model 8: $\chi^{2}=4.55,3 \mathrm{df}$, n.s.). Conversely, the two-loci model gave a significantly better fit than the single-locus model when the severity parameter was estimated for the modifier recessive gene (model 7 vs model 9: $\chi^{2}=14.89,4 d f, P=0.0049$ ). Among the different two-loci models tested a major dominant gene in linkage with D16S408 $(\theta=0.0)$ and a modifier recessive gene, with a major effect on severity of the trait, provided the most parsimonious hypothesis and therefore the best fit in our study (only the major recessive and modifier dominant model is shown: model 9 vs model 10, AIC: 279.98 vs 283.15). Under model 9 the recessive locus was found to have a major effect on severity of disease since $S_{m}$ was $>1$, whereas the inclusion of $\mathrm{S}$ for the dominant locus did not improve the likelihood (data not shown) and $\mathrm{S}$ was constrained to 0 . The two-loci model, where the recessive modifier locus contributes not only to affection but also to severity of disease, provided a significantly better fit than the simplifying hypothesis where $S_{m}=0$ (model 8 vs model 9: $\chi^{2}=10.34$, $1 \mathrm{df}, \mathrm{P}=0.0007$ ). Penetrances were estimated for each liability class under the identified two-loci model (model 9, Table4): homozygous individuals at the recessive locus showed complete penetrance in each liability class, whereas a reduced penetrance was estimated for heterozygous individuals at the dominant locus, with the highest estimated penetrance obtained for liability class 2 (penetrance $=13.5 \%$ for liability class 1 ; penetrance $=43.1 \%$ for liability class 2 ; penetrance $=37.9 \%$ for liability class 3 ). Probability for affected subjects of having either UC or CD for each gen otype was estimated under the same model: interestingly, all affected subjects with a recessive mode of inheritance were expected to develop CD, whereas approximately $70 \%$ of the patients with a dominant mode were estimated to present with UC and $30 \%$ with CD.

No other significant linkage was obtained for the remaining markers studied (all with lod scores $<1.0$, data not shown).

In order to evaluate whether a significant difference could be detected between $C D, U C$ and mixed families with respect to linkage to the IBD1 locus and to investigate the presence of genetic heterogeneity in our IBD sample, we performed the analysis on the following three sub-samples of families: $C D$

Table 4 Results of combined segregation and linkage analysis for the 82 IBD extended families (122 nuclear families)

\begin{tabular}{|c|c|c|c|c|c|c|c|c|c|c|c|}
\hline Model & $q$ & $\mathrm{t}$ & $d$ & $\mathrm{~S}$ & $\theta$ & $q_{m}$ & $t_{m}$ & $d_{m}$ & $\mathrm{~S}_{\mathrm{m}}$ & $-2 \ln L+C^{a}$ & $\mathrm{Z}^{\mathrm{b}}$ \\
\hline 1. ML dominant & 0.0075 & 5.16 & (1) & (0) & & (0) & & & & 297.84 & \\
\hline 2. ML recessive & 0.0795 & 7.53 & (0) & (0) & & (0) & & & & 330.43 & \\
\hline 3. ML additive & 0.0077 & 9.55 & $(0.5)$ & (0) & & (0) & & & & 297.72 & \\
\hline 4. ML general & 0.0077 & 9.91 & 0.80 & (0) & & (0) & & & & 297.72 & \\
\hline 5. Best 2-loci model & 0.0064 & 7.91 & 1 & (0) & & 0.0263 & 10.11 & 0 & $(0)$ & 287.82 & \\
\hline 6. Best 2-loci model+severity & 0.0066 & 5.59 & 1 & (0) & & 0.0226 & 18.30 & 0 & 0.84 & 274.95 & \\
\hline \multicolumn{12}{|l|}{ Best linkage (D16S408) } \\
\hline 7. Best ML model & 0.0077 & 5.56 & 1 & (0) & 0.0 & $(0)$ & & & & 278.87 & 4.14 \\
\hline 8. Best 2-loci model & 0.0069 & 4.82 & 1 & (0) & 0.0 & 0.0217 & 9.47 & 0 & $(0)$ & 274.32 & 2.93 \\
\hline 9. Best 2-loci model+ severity & 0.0067 & 5.01 & 1 & (0) & 0.0 & 0.0240 & 6.65 & 0 & 5.07 & 263.98 & 2.38 \\
\hline 10. ML recessive and modifier dominant & 0.0303 & 8.83 & 0 & 1.09 & 0.11 & 0.0069 & 8.52 & 1 & $(0)$ & 267.15 & 1.69 \\
\hline
\end{tabular}

$\mathrm{ML}=$ major locus; fixed parameters in parentheses; under model $9,87 \%$ of the affected subjects were estimated to have a at risk genotype.

aThe constant $C$ is present because calculations relating to ascertainment probability and marker typing are ignored since they are independent of the genetic model; ${ }^{b} Z$ is the two-point lod score calculated by taking the difference in $-2 \ln (\mathrm{L})+\mathrm{C}$ between linked and unlinked hypotheses and dividing by $2 \ln (10)$. 
Table 5 Results of combined segregation and linkage analysis for the IBD sub-samples

\begin{tabular}{|c|c|c|c|c|c|c|}
\hline Sample - ML models & q & $\mathrm{t}$ & $d$ & $\theta$ & $-2 \ln L+C$ & Z \\
\hline $\begin{array}{l}\text { CD-only families } \\
\text { 1. ML dominant } \\
\text { 2. ML recessive } \\
\text { 3. ML general } \\
\text { 4. ML dominant } \\
\text { 5. ML recessive } \\
\text { 6. ML general }\end{array}$ & $\begin{array}{l}0.0080 \\
0.0795 \\
0.0496 \\
0.0082 \\
0.0795 \\
0.0554\end{array}$ & $\begin{array}{r}3.73 \\
7.56 \\
9.19 \\
4.20 \\
8.79 \\
10.79\end{array}$ & $\begin{array}{l}(1) \\
(0) \\
0.27 \\
(1) \\
(0) \\
0.05\end{array}$ & $\begin{array}{l}0.0 \\
0.10 \\
0.09\end{array}$ & $\begin{array}{l}83.55 \\
80.53 \\
77.10 \\
72.28 \\
70.63 \\
67.78\end{array}$ & $\begin{array}{l}2.45 \\
2.15 \\
2.02\end{array}$ \\
\hline $\begin{array}{l}\text { UC-only families } \\
\text { 7. ML dominant } \\
\text { 8. ML recessive } \\
\text { 9. ML general } \\
\text { 10. ML dominant } \\
\text { 11. ML recessive } \\
\text { 12. ML general }\end{array}$ & $\begin{array}{l}0.0064 \\
0.0795 \\
0.0064 \\
0.0065 \\
0.0795 \\
0.0065\end{array}$ & $\begin{array}{l}5.37 \\
7.94 \\
5.73 \\
5.97 \\
8.01 \\
5.97\end{array}$ & $\begin{array}{l}(1) \\
(0) \\
1 \\
(1) \\
(0) \\
1\end{array}$ & $\begin{array}{l}0.0 \\
0.24 \\
0.0\end{array}$ & $\begin{array}{l}19.15 \\
41.00 \\
19.15 \\
12.54 \\
39.64 \\
12.54\end{array}$ & $\begin{array}{l}1.44 \\
0.30 \\
1.44\end{array}$ \\
\hline $\begin{array}{l}\text { CD/UC families } \\
\text { 13. ML dominant } \\
\text { 14. ML recessive } \\
\text { 15. ML general } \\
\text { 16. ML dominant } \\
\text { 17. ML recessive } \\
\text { 18. ML general }\end{array}$ & $\begin{array}{l}0.0090 \\
0.0937 \\
0.0096 \\
0.0092 \\
0.0944 \\
0.0098\end{array}$ & $\begin{array}{r}5.60 \\
5.47 \\
9.78 \\
5.09 \\
5.34 \\
10.84\end{array}$ & $\begin{array}{l}(1) \\
(0) \\
0.72 \\
(1) \\
(0) \\
0.44\end{array}$ & $\begin{array}{l}0.04 \\
0.33 \\
0.05\end{array}$ & $\begin{array}{l}192.41 \\
206.55 \\
191.66 \\
191.05 \\
206.35 \\
190.23\end{array}$ & $\begin{array}{l}0.30 \\
0.04 \\
0.31\end{array}$ \\
\hline
\end{tabular}

Number of extended families: CD only $=21 ; \mathrm{UC}$ only $=38 ; \mathrm{CD} / \mathrm{UC}=23$. Number of nuclear families: $C D$ only $=32 ; \mathrm{UC}$ only $=53 ; \mathrm{CD} / \mathrm{UC}=37$.

only, UC only, and mixed families, where CD and UC affected members were both present. Various models were tested, under both the hypotheses of no linkage and linkage to D16S408 (Table5).

When the analysis was limited to CD families, the best fit was obtained for the general model with an estimated dominance parameter, $\mathrm{d}$, of 0.05 and an estimated recombination fraction of 0.09 with a corresponding lod score of 2.02 (Table5, model 6). Co-existence of families favouring a dominant or a recessive model in the $C D$ sample might result in an overestimation of the recombination fraction for D16S408 when considering all the CD families jointly. In the analysis of the UC families a single dominant locus provided the best fit and positive indication of linkage was obtained at marker D16S408 under the dominant hypothesis, corresponding to a lod score of 1.44 at a recombination rate of 0.0 (Table5, model 12). In the mixed families, where affected subjects were both CD and UC, a lod score of 0.30 only was obtained with the dominant model. The two-loci models did not fit significantly better than the major locus models in IBD sub-samples (data not shown). No significant evidence for the presence of heterogeneity could be detected (all $P$ values $>0.05$ ).

\section{Discussion}

This study, based on combined segregation and linkage analysis of 82 extended Italian families, provides a genetic model for IBD, CD, and UC, insights into their relationship, and elucidates the role of the IBD1 locus in their aetiology.
Considering $C D$ and UC jointly, significant evidence for a two-loci model with a recessive and a dominant mode of inheritance was obtained and the inclusion of severity information allowed us to ascribe to $C D$, the more severe class, a recessive mode of inheritance. Furthermore, considering $C D$ and UC families separately, evidence for the presence of a major gene with an estimated dominance parameter close to the recessive case was obtained for $C D$, whereas evidence for a dominant major gene was obtained for UC.

Two-point linkage tests performed in the IBD1 region gave evidence for linkage to marker D16S408 for the single dominant model (lod score of 4.14). In the two-loci hypotheses, both putative major genes were found to be linked to D16S408 when assuming either a dominant or a recessive major gene linked to the marker locus. Considering the IBD sub-samples separately, a lod score of 2.02 and a lod score of 1.44 were obtained for marker D16S408 in the CD and UC samples, respectively.

These results suggest that both putative major genes are located close to D16S408 in the IBD1 region and the possibility that they represent the same gene cannot be ruled out. A common genetic aetiology for both forms of IBD is obtained in our study with respect to the IBD1 locus and it can be postulated that a major gene, involved in both UC and CD aetiology, is present in the IBD1 region close to D16S408. From our analysis we estimated that a single mutation in the gene leads more frequently to UC, whereas a double copy of the mutant allele would result in the more severe CD.

In our previous study ${ }^{26}$ a peak multipoint non-parametric linkage score of $2.71(P=0.0035)$, corresponding to a lod score of $1.59\left(=2.71^{2} / 2 \ln 10\right)$ was obtained at the same marker identified in this analysis (namely D16S408), 
although evidence of linkage ( $P$ values $<0.05$ ) was observed over a $27 \mathrm{cM}$ interval of the IBD1 region. Comparison with the previous analysis is not straightforward since in Annese et al a non-parametric method based on IBD-sharing in affected relatives was utilised in a reduced sample of families presenting at least two affected subjects (other than the parent-child pair). This approach provides a low resolution mapping, since observed recombinations do not exclude a chromosome region but render it only less likely.

Our results from segregation analysis are concordant with results obtained by Orholm et al, ${ }^{10}$ where a major recessive gene was found for $C D$ and a major dominant gene was found for UC, although the two traits were analysed separately and linkage was not considered in their study.

Combined segregation and linkage analysis not only allows a more accurate estimation of the genetic parameters, since marker data provide extra information when linkage is present, but also increases the power to detect linkage. In the study of complex traits, when a segregation model cannot be defined with certainty, but the presence of major genes (or oligogenes) is suspected, combined segregation and linkage analysis at specific loci previously mapped by linkage analysis remains an attractive and a powerful approach.

\section{Acknowledgements}

We thank the patients and their families who provided blood samples for the study. We also wish to thank Dr E Rappaport and two anonymous reviewers for their helpful comments and suggestions on this manuscript. The following investigators of the Italian Group for the Study of the Colon and Rectum (GISC) provided the family sample: G Iaquinto, I Sorrentini (Avellino); M Campieri, P Gionchetti, S Peruzzo (Bologna); D Valpiani, D Imperio (Forlì); G Frieri, MT Pimpo, R Caprilli (L'Aquila); S Giaccari, L Grasso (Galatina); G Riegler, F Morace, S Cucchiara (Napoli); A Andreoli, C Prantera, G Milite (Roma); GC Sturniolo, R D'Incà (Padova); M Astegiano, M Rizzetto, F Bresso, A Pera (Torino), G Lombardi, G Napolitano, A Piepoli, P Bovio (San Giovanni Rotondo). This work was supported in part by a grant from the Department of Pathology at the Children's Hospital of Philadel phia, USA.

\section{References}

1 Sandler RS: Epidemiology of inflammatory bowel disease. In: Targan SR, Shanahan F (eds). Inflammatory Bowel Disease. From Bench to Bedside. Williams \& Wilkins: Baltimore, 1994; pp 5-31.

2 Lennard-Jones JE: Classification of inflammatory bowel disease. Scand J Gastroenterol 1989; 24(suppl. 170): 2-6.

3 Thompson NP, Driscoll R, Pounder RE, Wakefield AJ: Genetics versus environment in inflammatory bowel disease: results of a British twin study. BJK 1996; 312: 95-96.

4 Satsangi J, Jewell DP, Bell JI: The genetics of inflammatory bowel disease. Gut 1997; 40: 572-574.

5 Fielding JF: The relative risk of inflammatory bowel disease among parents and siblings of Crohn's disease patients. J Clin Gastroenterol 1986; 8: 655-657.

6 Orholm M, Munkholm P, Langhoiz E, Nielsen OH, Sorensen TIA, Binder V: Familial occurrence of inflammatory bowel disease. New Engl J Med 1991; 324: 84-88.
7 McConnell RB: Genetics of inflammatory bowel disease. In: Allan RN, Keighley MRB, Alexander-Williams J, Hawkins C (eds). Inflammatory Bowel Disease. Churchill-Livingstone: London, 1990, pp 11-23.

8 Kuster W, Pascoe L, Purrmann J, Funk S, Majewski F: The genetics of Crohn disease: complex segregation analysis of a family study with 265 patients with Crohn disease and 5,387 relatives. Am J Hum Genet 1989; 32: 105-108.

9 Monsen U, Iselius L, Johansson C, Hellers G: Evidence for a major additive gene in ulcerative colitis. Clin Genet 1989; 36: 411-414.

10 Orholm M, Iselius L, Sorensen $\mathrm{TI}$ et al: Investigation of the inheritance of chronic inflammatory bowel disease by complex segregation analysis. BMJ 1993; 306: 20-24.

11 Hugot JP, Puig PL, Gower-Rousseau C et al: Mapping of susceptibility locus for Crohn's disease on chromosome16. Nature 1996; 379: 821-823.

12 Satsangi J, Parkes M, Louis E et al: Two stage genome-wide search in inflammatory bowel disease provides evidence for susceptibility loci on chromosomes3, 7 and 12. Nat Genet 1996; 14: 199-202.

$13 \mathrm{Cho} \mathrm{JH}$, Nicholae DL, Gold LH et al: Identification of novel susceptibility loci for inflammatory bowel disease on chromosomes $1 p, 3 q$, and $4 q$ : evidence for epistasis between $1 p$ and IBD1. Proc Natl Acad Sci USA 1998; 95: 7502-7507.

14 Hampe J, Schreiber S, Shaw S et al: A genomewide analysis provides evidence for novel linkages in inflammatory bowel disease in a large European cohort. Am J Hum Genet 1999; 64: 808-816.

$15 \mathrm{Ma} \mathrm{Y}$, Ohmen JD, Li Z et al: A genome-wide search identifies potential new susceptibility loci for Crohn's disease. Inflamm Bowel Dis 1999; 5: 271-278.

16 Rioux JD, Silverberg MS, Daly MJ et al: Genomewide search in Canadian families with inflammatory bowel disease reveals two novel susceptibility loci. Am J Hum Genet 2000; 66: 1863-1870.

17 Ohmen JD, Yang HY, Yamamoto KK et al: Susceptibility locus for inflammatory bowel disease on chromosome 16 has a role in Crohn's disease, but not in ulcerative colitis. Hum Mol Genet 1996; 10: 1679-1683.

18 Parkes M, Satsangi J, Lathrop GM, Bell JI, Jewell DP: Susceptibility loci in inflammatory bowel disease. Lancet 1996; 348: 1588.

$19 \mathrm{Cho} \mathrm{JH}, \mathrm{Fu} \mathrm{Y,} \mathrm{Kirschner} \mathrm{BS,} \mathrm{Hanauer} \mathrm{SB:} \mathrm{Confirmation} \mathrm{of} \mathrm{a}$ susceptibility locus for Crohn's disease on chromosome16. Inflamm Bowel Dis 1997; 3: 186-190.

20 Duerr RH, Barmada MM, Zhang $L$ et al: Linkage and association between inflammatory bowel disease and a locus on chromosome12. Am J Hum Genet 1998; 63: 95-100.

21 Mirza MM, Lee J, Teare D et al: Evidence of linkage of the inflammatory bowel disease susceptibility locus on chromosome16 (IBD1) to ulcerative colitis. J Med Genet 1998; 35: 218-221.

22 Brant SR, Fu Y, Fields CT et al: American families with Crohn's disease have strong evidence for linkage to chromosome 16 but not chromosome12. Gastroenterology 1998; 115: 1056-1061.

23 Curran ME, Lau KF, Hampe J et al: Genetic analysis of inflammatory bowel disease in a large European cohort supports linkage to chromosomes 12 and 16. Gastroenterology 1998; 115: 1066-1071.

24 Cavanaugh JA, Callen DF, Wilson SR et al: Analysis of Australian Crohn's disease pedigrees refines the localization for susceptibility to inflammatory bowel disease on chromosome16. Ann Hum Genet 1999; 62: 291-298.

25 Hampe J, Show SH, Saiz R et al: Linkage of inflammatory bowel disease to human chromosome6p. Am J Hum Genet 1999; 65: 1647-1655.

26 Annese V, Latiano A, Bovio P et al: Genetic analysis in Italian families with inflammatory bowel disease supports linkage to the IBD1 region - a GISC study. Eur J Hum Genet 1999; 7: 567-573.

27 Lalouel JM, Morton NE: Complex segregation analysis with pointers. Hum Hered 1981; 31: 312-321. 
28 Morton NE, Rao DC, Lalouel JM: Methods in Genetic Epidemiology. Karger: Basel, 1983.

29 Morton NE, MacLean CJ: Analysis of family resemblance III. Complex segregation analysis of quantitative trait. Am J Hum Genet 1974; 26: 318-330.

30 Tragnone A, Corrao G, Miglio F, Caprilli R, Lafranchi GA: Incidence of inflammatory bowel disease in Italy: a nationwide population-based study. Gruppo Italiano per lo Studio del Colon e del Retto. Int J Epidemiol 1996; 25: 1044-1052.
31 Morton NE, Shields DC, Collins A: Genetic epidemiology of complex phenotypes. Ann Hum Genet 1991; 55: 301-314.

32 Akaike $\mathrm{H}$ : A new look at the statistical model identification. IEEE Trans Automatic Control 1974; 19: 716-723. 